\title{
Sistem Informasi Rektrutmen Calon Perangkat Desa sebagai Ruang Partisipasi Warga dan Pemerintah Desa Cangkring Rembang Karanganyar Demak
}

\author{
Mukhamad Nurkamid ${ }^{1}$, Ahmad Jazuli ${ }^{2}$, Muhammad Imam Ghazali ${ }^{3}$ \\ ${ }^{1}$ Program Studi Teknik Informatika, Fakultas Teknik, Universitas Muria Kudus \\ Gondangmanis PO BOX 53 Bae Kudus 59327, 0291-438229, e-mail: \\ muhammad.nurkamid@umk.ac.id \\ 2 Program Studi Teknik Informatika, Fakultas Teknik, Universitas Muria Kudus \\ Gondangmanis PO BOX 53 Bae Kudus 59327, 0291-438229, e-mail:ahmad.jazuli@umk.ac.id. \\ ${ }^{3}$ Program Studi Teknik Informatika, Fakultas Teknik, Universitas Muria Kudus \\ Gondangmanis PO BOX 53 Bae Kudus 59327, 0291-438229, e-mail:imam.ghazali@umk.ac.id.
}

\section{ARTICLE INFO}

Article history:

Received 22 June 2019

Received in revised form 05 July 2019

Accepted 25 July 2019

Available online 31 July 2019

\section{ABSTRACT}

The purpose of this study is to produce a recruitment system for prospective village officials that is applied to the system of governance in the village of Cangkring Rembang, Karanganyar Demak District. Cangkring Rembang Demak village government in carrying out its duties, principal and government functions is one of them is the process of recruiting prospective village officials is still done manually. With manual systems documents can be lost, damaged and stored in several different storage spaces. In addition, the verification process for prospective applicant data takes a long time. Another disadvantage, if the document is needed at any time for public publication needs is not recorded properly so that it can not be used as decision making quickly. The application development method uses the waterfall approach. The results of this study are a recruitment system for prospective village adaptives that can provide solutions for prospective applicants, especially in the process of recruiting prospective village officials. With this system, in addition to documents, it is easy to store in the online storage room, the implementation of recruitment of prospective village officials can be transparent and participatory.

Keywords: recruitment, village officials, online storage.

\section{Pendahuluan}

Populasi pengguna internet kian hari meningkat secara signifikan setiap tahunnya. Data Asosiasi Penyelenggara Jasa Internet Indonesia (APJII) tahun 2017 saja telah mencapai 143 juta dari 262 juta $(54,5 \%)$. Dan itu artinya lebih dari setengah populasi penduduk Indonesia saat ini telah menggunakan internet untuk menunjang aktifitas kesehariannya. Distribusi penggunaan internet berdasar letak geografis pulau jawa masih memimpin dengan $50,70 \%$, selanjutnya Sumatra dengan 19,09\%, Kalimatan 7,97\%, Sulawesi 6,73\%, Bali-Nusa 5,63\% dan MalukuPapua 2,49\%. Segmentasi usia pengguna internet masih didominasi usia muda, dengan 49,52\%. Ini menunjukkan dari data 262 juta kurang lebih ada 129 juta pengguna internet kategori anak muda berusia 19-34 tahun [1]. 
Penggunaan intenet tidak bisa dipisahkan dalam kehidupan sehari-hari. Pemanfaatannya (internet) telah banyak digunakan diberbagai segi bidang kehidupan, mulai untuk transportasi, perdagangan (bisnis), pendidikan, hiburan dan sistem pemerintahan. Terlebih, survei APJII tahun 2017 dari 143,26 juta masyarakat Indonesia yang sudah terkoneksi internet, ada sekitar 62,58 $(43,68 \%)$ juta masyarakat kelas menengah ke bawah yang menggunakan internet. Sedangkan masyarakat kelas atas sebesar 2,83 (1,97\%) juta jiwa [2].

Pemerintahan Desa Cangkring Rembang Kecamatan Karanganyar Kabupaten Demak dalam menjalankan tugas, pokok dan fungsi pemerintahan salah satunya proses seleksi penerimaan calon perangkat desa masih dikerjakan dengan cara manual. Pelamar datang membawa berkas (persyaratan) untuk dikumpulkan, panitia melakukan verifikasi berkas yang di dampingi beberapa saksi dan hasilnya dilaporkan kepada kepala desa. Selain kurang efisien, dengan sistem manual tersebut dokumen dapat hilang, rusak dan tersimpan dibeberapa ruang penyimpanan. Kelemahan lainnya jika dokumen sewaktu-waktu dibutuhkan untuk keperluan masyarakat biasanya membutuhkan waktu pencarian yang relatif lama. Selain kelemahan disisi administrasi, faktor pembiayaanpun menjadi lebih besar karena melibatkan berbagai stakholder di dalam proses seleksi calon perangkat desa. Stakholder tersebut misalnya petugas uji komputer yang secara khusus terlibat untuk menguji calon perangkat desa.

Penerapan sistem informasi dikalangan pemerintah daerah (e-govermnet) menjadi komitmen semua pihak untuk mewujudkan sistem pemerintahan yang transparan dan akuntabel. Kongkret penerapan sistem informasi pemerintah daerah atau yang di kenal dengan istilah $e$ goverment sudah diterapkan oleh Pemerintah Bandung Barat melalui nota kesepahaman dengan Komisi Pemberantas Korupsi (KPK). Penerapan sistem e-goverment tersebut tidak hanya membuat sistem pemerintahan berjalan efektif dan efisien tetapi juga bisa mencegah terjadinya tindak pidana korupsi, kolusi dan nepotisme. Sebab laporan-laporan dikerjakan secara online dan transparan sehingga masyarakat dapat mengetahui dan mengawasi jalannya pemerintahan [3].

Saat ini, terjadi perubahan era baru dimana pola hubungan pemerintah dengan masyarakat sudah berubah. Masyarakat menginginkan transparansi, menginginkan keterbukaan informasi publik, dan menginginkan agar pemerintah dan masyarakat interaktif, yang dialogis, responsif, yang cepat merespon keluhan-keluhan yang disampaikan oleh masyarakat[4]. Dengan sistem pemerintahan daerah yang terbuka mendorong partisipasi masyarakat tumbuh dan beradaptasi. Karakteristik sistem pemerintahan terbuka dapat diklasifikasikan menjadi empat bagian: (1) Pemerintah menyediakan berbagai informasi terkait kebijakan yang telah dibuatnya, (2) Adanya peluang bagi publik untuk mendapatkan atau mengakses berbagai dokumen pemerintah, (3) terbukanya ruang-ruang pemerintah bagi publik dan pers, dan terakhir adanya konsultasi publik yang dilakukan secara sistematik oleh pemerintah. Konsultasi publik ini berkaitan dengan perumusan dan pelaksanaan kebijakan, terlebih diera keterbukaan informasi seperti dewasa sekarang ini[5]. Teknologi informasi telah menjadi salah satu infrastruktur utama dalam kehidupan masyarakat modern layaknya listrik, air dan jalan, karena teknologi informasi dapat berperan sebagai sumber daya produksi dan konsumsi manusia sekaligus sebagai piranti pendukung dalam pelaksanaan kegiatan sehari-hari baik yang bersifat pemerintahan, industri, organisasi, maupun kemasyakatan [6]. Manfaat yang bisa dirasakan oleh pemerintahan dengan implementasi teknologi informasi selain memudahkan monitoring dan evaluasi, mengoptimalkan ketercapaian tujuan internal manajemen juga dapat meningkatan kualitas pelayanan publik yang lebih baik[7].

Beberapa penelitian tentang tema rukretmen pemilihan calon perangkat desa telah banyak dilakukan, salah satunya hasil penelitian dari Burhanudin Mukhamad Faturahman (2018) yang dimuat dalam jurnal sospol berjudul "Aktualisasi Nilai Demokrasi dalam Perekrutan dan Penjaringan Perangkat Desa". Hasil penelitian tersebut menunjukkan bahwa proses perekrutan dan penjaringan perangkat desa di desa Tiremenggal Kabupaten Gresik sebaiknya dilakukan secara transparan. Transparansi yang dibangun sangat penting dalam menjaga kehidupan berdemokrasi, terlebih masyarakat dilibatkan dalam proses rekrutmen tersebut. Sehingga secara tidak langsung dengan transparansi tersebut dapat menjaga keharmonisan sosial jalannya program pemerintahan desa[8]. 
Penelitian kedua dari Rose Siti Badriyah (2017) yang dimuat dalam jurnal ilmiah Ilmu Administrasi Negara yang berjudul "Pengaruh Rekruitmen Perangkat Desa Terhadap Kinerja Perangkat Desa di Desa Andapraja Kecamatan Rajadesa Kabupaten Ciamis”. Hasil penelitian tersebut mengungkapkan bahwa ada pengaruh rekrutmen perangkat desa terhadap kinerja perangkat desa di Desa Andapraja. Sehingga tindak lanjutnya adalah pemerintah desa diminta untuk memperbaiki indikatorindikator rekrutmen, dan jika indikator yang ditetapkan baik akan berdampak pada hasil rekrutmen yang lebih optimal[9].

Persamaan dan perbedaan pada penelitian terdahulu adalah persamaannya, sama-sama mengambil objek penelitian tentang rekrutmen perangkat desa. Perbedaannya adalah pada penelitian ini telah dibangun inovasi sistem rekrutmen calon perangkat desa yang lebih baik dan adaptif yang dapat digunakan untuk proses dan jalannya rekrutmen calon perangkat desa sehingga pelaksanaan rekrutmen berjalan demokratis. Misalnya, setiap peserta dapat mengikuti ujian sesuai jenis (tipe) formasi lowongan yang dibutuhkan oleh desa.

\section{Metode Penelitian}

Metode yang digunakan pada penelitian ini menggunakan waterfall. Desain waterfall menggunakan beberapa pendekatan yaitu: analisa kebutuhan, desain sistem, implementasi dan pengujian unit (modul), integrasi dan pengujian sistem secara keseluruhan dan perbaikan [10].

a. Analisa kebutuhan (requirement analysis)

Mengidentifikasi semua kebutuhan modul-modul (unit) sistem rekrutment yang dibangun dan batasan-batasannya.

b. Desain sistem (system design)

Membuat desain perancangan sistem, desain basisdata, desain kebutuhan hardware dan software.

c. Implementasi dan pengujian unit (implementation and unit testing)

Mengimplementasikan sistem dengan melakukan verifikasi data dan pengujian unit.

d. Integrasi dan pengujian sistem (integration and system testing)

Melakukan integrasi sistem dengan melakukan pengujian secara keseluruhan sistem sebelum diberikan kepada pengguna.

e. Penggunaan dan perbaikan (operation and system maintenance)

Tahapan paling akhir dari siklus perangkat lunak yaitu pelatihan bagi pengguna dan perbaikan jika ditemukan fitur yang tidak sesuai.

\section{Hasil dan Analisa}

Teknologi informasi didefinisikan sebagai segala hal yang berkaitan dengan proses, manipulasi teknologi pengolahan dan penyebaran data dan informasi dengan menggunakan hardware dan software, komputer, komunikasi, dan elektronik digital secara tepat dan efektif[11]. Teknologi informasi disusun oleh teknologi komputer yang menjadi pendorong utama perkembangan aplikasi saat ini yang kian hari kian bertambah besar.

Dalam penelitian ini telah dikembangkan domain teknologi informasi untuk sistem rekrutmen berbasis web menggunakan pendekatan bahasa pemrograman PHP dan basisdata MySQL. Sistem rekrutmen memiliki beberapa fitur yang masing-masing dikelola oleh administrator, panitia seleksi, peserta dan kepala desa.

Kegiatan yang dikelola panitia meliputi:

a. Melihat daftar peserta

b. Menambahkan soal ujian untuk peserta

c. Mengelola persyaratan peserta 
d. Melihat nilai hasil ujian peserta

e. Mencetak laporan peserta

Sedangkan pada peserta terdapat beberapa fitur, diantaranya:

a. Mendaftar sebagai peserta

b. Melihat persyaratan rekrutmen

c. Mengunduh persyaratan

d. Mengunggah dokumen persyaratan rekrutmen

e. Mengerjakan ujian (test)

f. Melihat hasil ujian (test)

g. Mengganti password

Sedangkan pada bagia adnministrator terdapat beberapa fitur, diantaranya:

a. Mendaftarkan peserta ujian

b. Input data panitia

c. Seting data peserta ujian

d. Seting soal ujian peserta

e. Seting jadwal dan waktu ujian

f. Input peserta ujian

g. Melihat hasil ujian

Sedangkan pada menu kepala desa terdapat beberapa fitur, diantaranya:

a. Melihat data peserta

b. Melihat soal yang diujikan

c. Melihat hasil ujian peserta

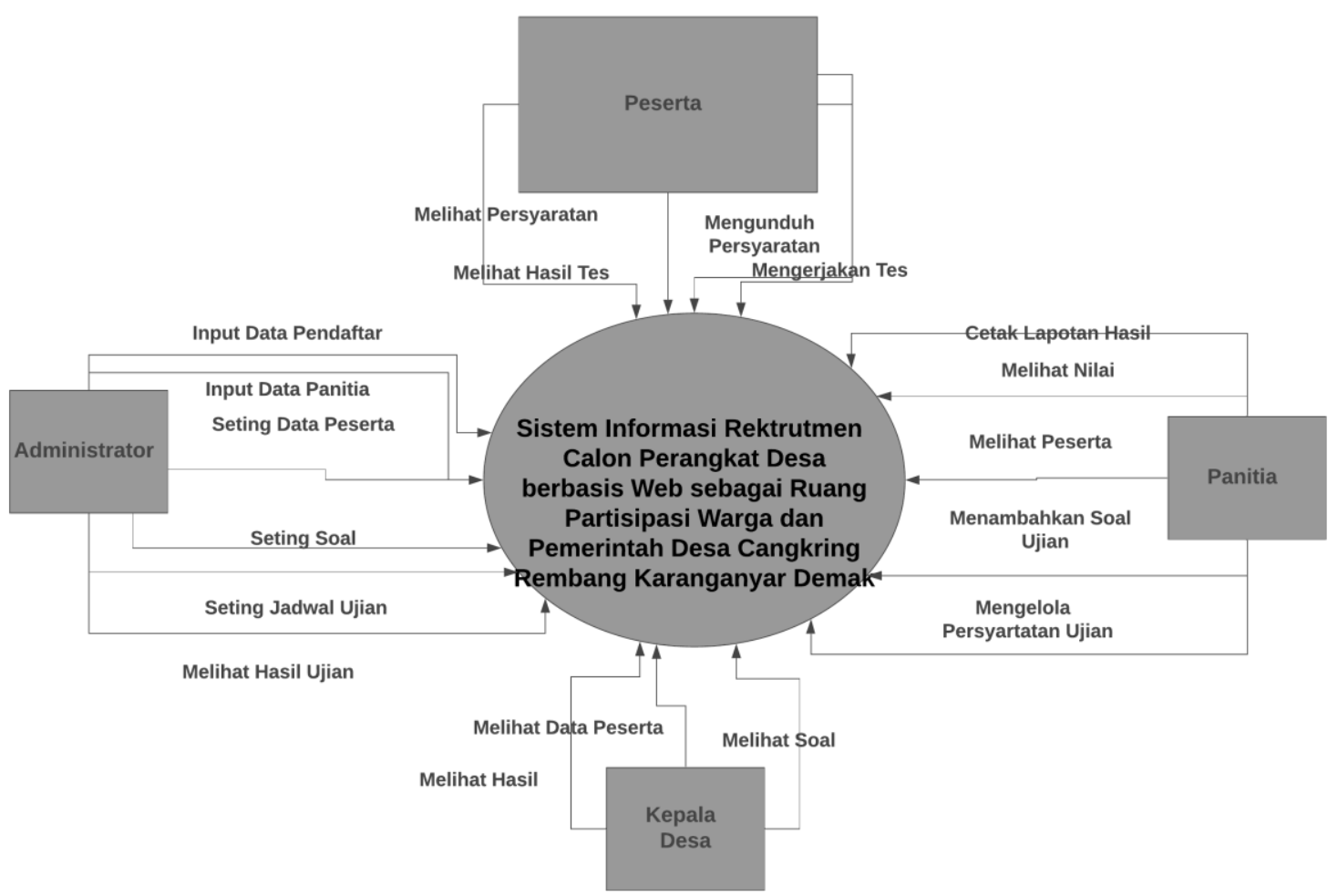

Gambar 1. Context diagram sistem rekrutmen pada Desa Cangkringrembang Karanganyar Demak. 
Dalam diagram konteks (context diagram) memperlihatkan secara umum aktivitas yang terjadi di dalam lingkup sistem rekrutmen. Aktivitas tersebut dikerjakan oleh beberapa entitas yang saling terkait dan membagi tugas satu sama lain seperti entitas administrator, panitia seleksi, peserta dan kepala desa. Setiap aktivitas yang disajikan pada diagram konteks menunjukkan bahwa setiap entitas memiliki spesifikasi tugas masing-masing. Misalnya, entitas panitia bertugas menambahkan (menyiapkan) soal-soal dan jenis ujian yang akan diujikan. Sedangkan petugas administrator bertugas membuat jadwal dan jenis ujian yang akan diikuti oleh peserta. Sedangkan entitas peserta dapat melihat semua kebutuhan persyaratan, mengunggahnya kembali dan mengerjakan ujian (test) sedangkan kepala desa dapat melihat hasil ujian dan peserta yang mengikuti seleksi.

Secara umum langkah-langkah proses rekurtmen calon perangkat desa di desa Cangkringrembang dapat sajikan pada gambar 2 .

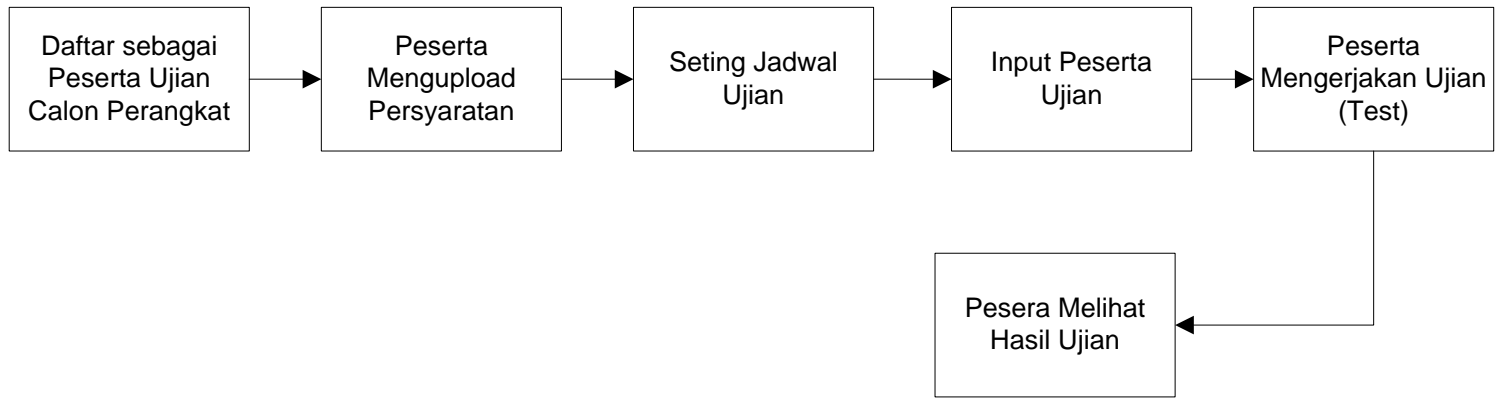

Gambar 2. Langkah-langkah Proses Rekrutmen Calon Perangkat Desa 


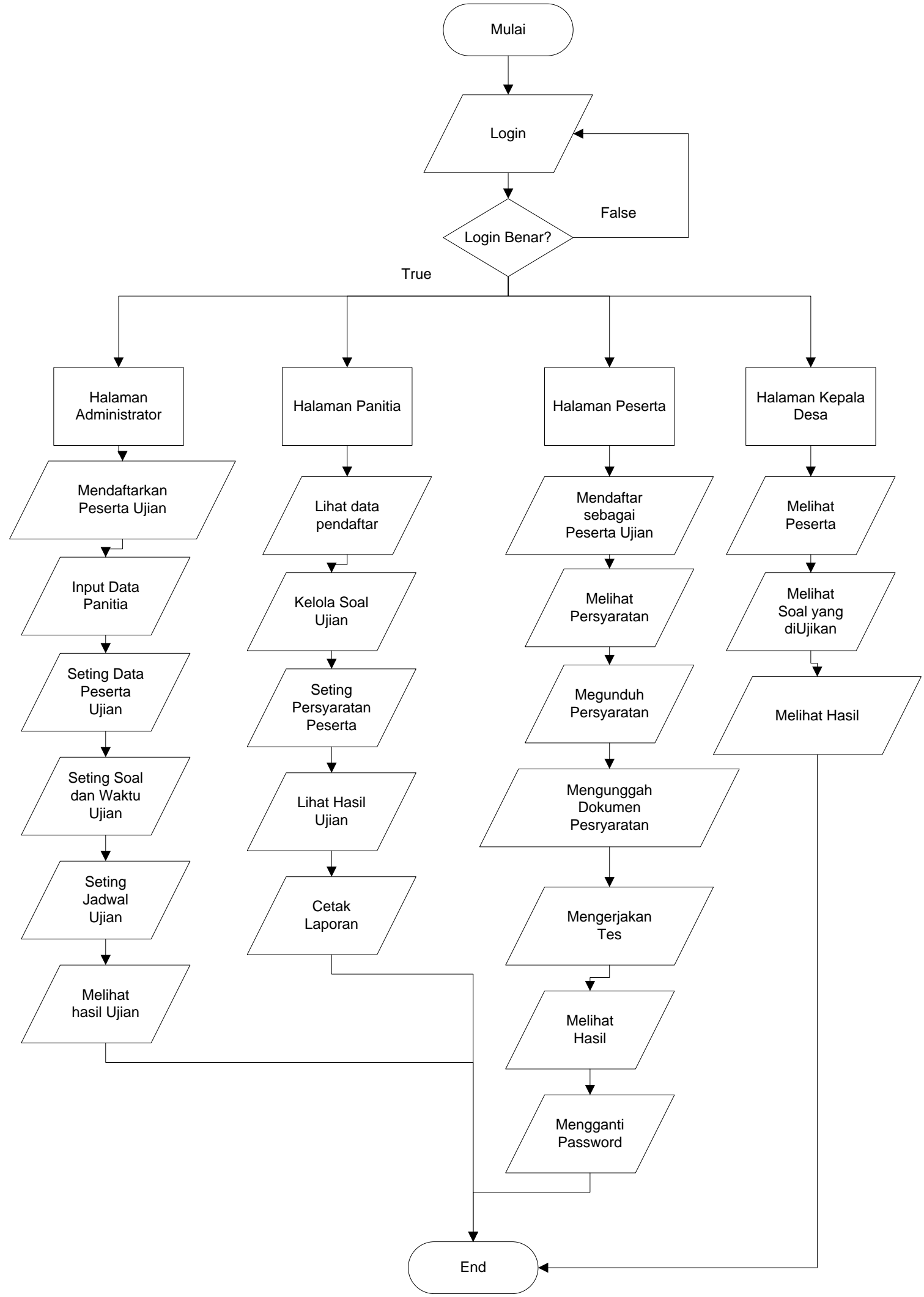

Gambar 3. Flowchart sistem rekrutmen pada Desa Cangkringrembang Karanganyar Demak 
Pada tahapan implementasi memperlihatkan sebelum peserta mengerjakan soal ujian, setiap peserta wajib melengkapi semua persyaratan yang dibutuhkan. Tahapan pertama adalah panitia menginputkan soal-soal yang akan diujikan. Soal dibuat sesuai kebutuhan yang telah disepakati bersama bertipe multiple choice. Sedangkan administrator memiliki kewenangan menentukan jadwal ujian yang akan dikerjakan oleh peserta. Kewajiban peserta sebelum dapat mengerjakan soal, adalah melengkapi semua persyaratan yang telah ditentukan pihak desa melalui panitia yang telah dibentuk dan mengunggah kembali semua persyaratan. Apabila persyaratan-persyaratan yang telah ditentukan panitia dan diunggah peserta masih ditemukan kesalahan, peserta wajib memperbaiki dokumen sebelumnya (gambar 3). Hal ini dilakukan agar proses pelaksanaan rekutmen berjalan obyektif. Hasil dari pelaksanaan ujian (test) pihak desa melalui kepala desa dapat melihat dengan jelas seluruh instrumen yang ada mulai dari soal yang diujikan, data peserta yang mengikuti ujian dan hasil ujian.

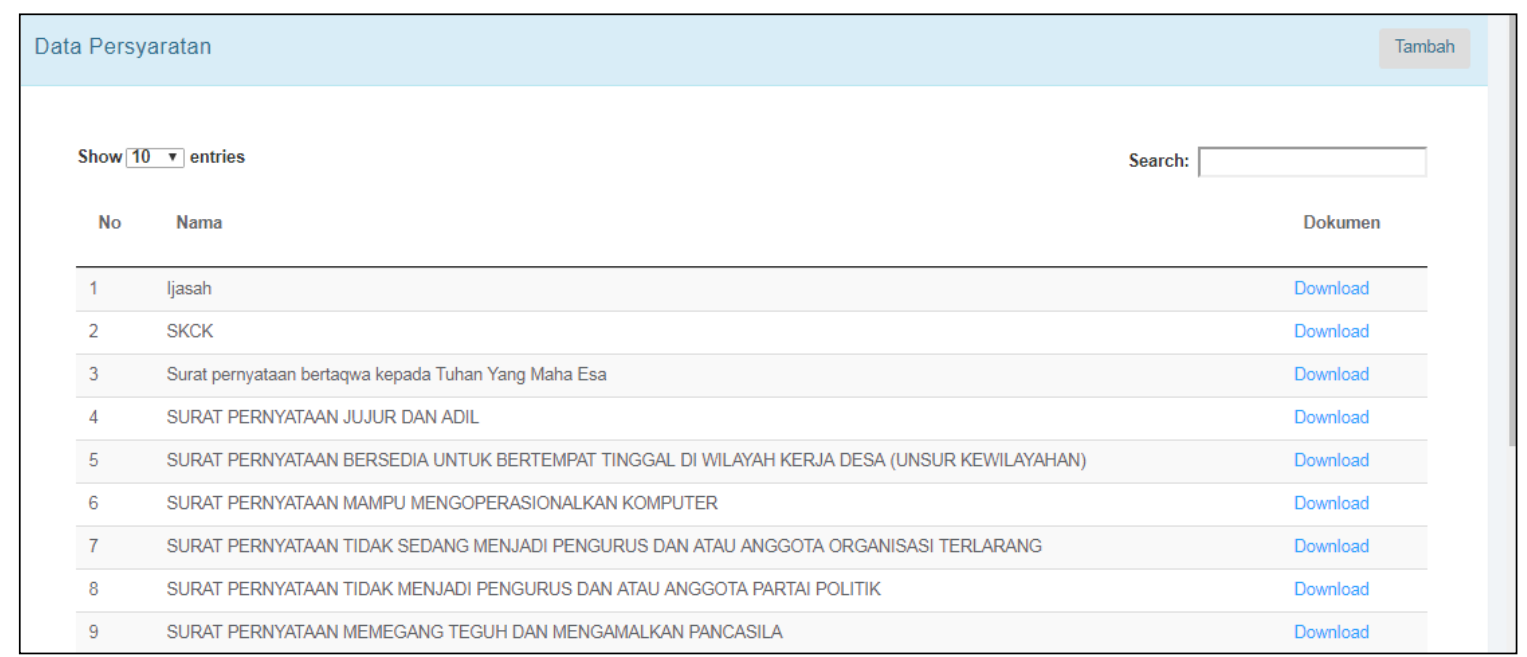

Gambar 4. Data persyaratan calon peserta yang ditentukan oleh panitia.

Pada gambar 4 memperlihatkan beberapa contoh persyaratan dokumen yang harus di unggah peserta sebelum mengerjakan tes sebagai calon perangkat desa Cangkringrembang. Pada halaman panitia (dashboard), semua dokumen yang di unggah oleh peserta dapat diunduh dan dilakukan verifikasi.

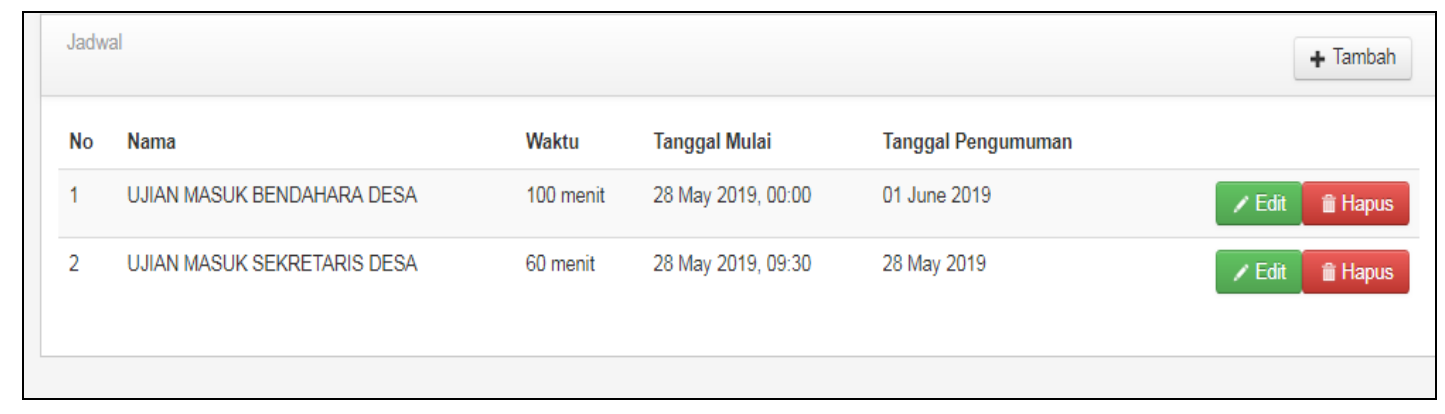

Gambar 5. Seting Jadwal Ujian 
Pada gambar 5 memperlihatkan beberapa ujian dan tanggal ujian yang akan diikuti oleh peserta ujian (test) calon perangkat desa. Jadwal tersebut di kerjakan oleh petugas administrator desa. Pada sistem rekrutmen calon perangkat desa terdapat beberapa jenis ujian untuk beberapa formasi perangkat desa.

\section{Kesimpulan}

Hasil dari penelitian ini adalah prototipe sistem informasi rekrutmen yang dapat digunakan untuk membantu jalannya kegiatan administrasi rektrutmen calon perangkat desa oleh pemerintah desa Cangkringrembang Kecamatan Karanganyar Kabupaten Demak. Manfaat yang diperoleh dengan sistem rekrutmen, pertama warga dapat berpartisipasi secara online menggunakan sistem sehingga dokumen dapat terarsip lebih baik jika sewaktu-waktu dibutuhkan dalam proses seleksi. Kedua, pelaksanaan seleksi dapat berjalan transparan, karena proses seleksi dapat di monitor dan di evaluasi. Dan ketiga membuat proses pelaksanaan seleksi lebih cepat, karena membagi tugas menjadi beberapa bagian dan dilaksanakan oleh pihak-pihak tertentu seperti panitia, peserta, operator desa dan kepala desa sehingga kualitas pelayanan publik lebih baik.

\section{References}

[1] Bohang, F., K. 2018. Berapa Jumlah Internet Indonesia. https://tekno.kompas.com/read/2018/02/22/16453177/berapa-jumlah-pengguna-internetindonesia (22 Februari 2018).

[2] Pratiwi., W.,K. 2018. Masyarakat Kelas Menengah ke Bawah Dominasi Internet di Indonesia. $\quad$ https://tekno.kompas.com/read/2018/02/22/07520057/masyarakat-kelasmenengah-ke-bawah-dominasi-internet-di-indonesia (22 Februari 2018).

[3] Wijaya Sari, C., 2017. Sistem Manual di Pemerintahan Sudah Ketinggalan Zaman. http://www.pikiran-rakyat.com/bandung-raya/2017/10/30/sistem-manual-di-pemerintahansudah-ketinggalan-zaman-412669 (30 Oktober 2017).

[4] Widodo, J. 2015. Penggunaan Sistem E-Government Syarat Pemerintah Terbuka. http://www.presidenri.go.id/berita-aktual/presiden-jokowi-penggunaan-sistem-egovernment-syarat-pemerintah-terbuka.html ( 1 Februari 2018).

[5] Undang Undang No 14 tahun 2008. Undang-Undang Republik Indonesia tentang Keterbukaan Sistem Informasi.

[6] Amri. 2016. Analisis Pemanfaatan Teknologi Informasi dan Komunikasi Dalam Menunjang Terwujudnya Makasar sebagai Smart City. Jurnal Komunikasi Kareba, Vol.5, No.2 Desember 2016. Program Studi Ilmu Komunikasi Universitas Hasanuddin.

[7] Putra, B., R., Sensuse., D.,I., 2008. Rancangan Tata Kelola TI untuk Institusi Pemerintah Studi Kasus Bappenas. Jurnal Sistem Informasi MTI Vol.4, No.1, Fakultas Ilmu Komputer, Universitas Indonesia, Jakarta.

[8] Muhammad Faturahman, B., 2018. Sistem Rekrutmen Calon Perangkat Desa. Jurnal Sospol Vol 4, No.1, (Januari-Juni 2018), Universitas Muhammadiyah Malang, Malang (http://ejournal.umm.ac.id/index.php/sospol/article/download/5557/5328).

[9] Badriyah, R.S., 2017. Pengaruh Rekruitmen Perangkat Desa Terhadap Kinerja Perangkat Desa Di Desa Andapraja Kecamatan Rajadesa Kabupaten Ciamis. Jurnal Ilmiah Administrasi Publik Dinamika, Vol.4, No.3, Program Studi Ilmu Administrasi Negara, Fakultas Ilmu Sosial dan Ilmu Politik, Universitas Galuh (Unigal), Ciamis, Jawa Barat. (https://jurnal.unigal.ac.id/index.php/dinamika/article/view/661).

[10] Sommerville, I., 2011. Software Engineering Ninth Edition, Addison Wesley. USA.

[11] McLeod, Raymond., 2010. Sistem Informasi Manajemen, Salemba. Jakarta. 